\section{THE GRAIN SIZE INFLUENCE ON BORON DOPED DIAMOND SENSITIVITY FOR ELECTROCHEMICAL REDUCTION OF NITRATE}

\author{
Jorge T. Matsushima, Adriana F. Azevedo, Maurício R. \\ Baldan, Neidenêi G. Ferreira, \\ neidenei@las.inpe.br \\ Laboratório Associado de Sensores e Materiais, \\ INPE, 12245-970, S J Campos, SP Brazil
}

The excessive presence of nitrate ions $\left(\mathrm{NO}_{3}{ }^{-}\right)$in water mainly caused by the fertilizing in agriculture process may promote dangerous ecological complications [1]. Considering different methodologies to detect and to destruct nitrate ions, the electrochemical process appears as a promising and cheaper technique [2]. Due to its singular electrochemical properties, boron doped diamond electrodes have shown good efficiency for eletrolyses and nitrate reduction [3]. None the less, the diamond properties may depend on the different experimental conditions such as doping level and $\mathrm{sp}^{2} / \mathrm{sp}^{3}$ ratio that influence the film grain size and also its crystallographic orientation. This work presents the electrochemical behavior for nitrate reduction using heavily doped diamond electrodes produced at different growth times that represents an evolution in the film grain size. These different morphologies may determine the better physical-chemical characteristic for electroanalytical applications.

The films were prepared by hot filament CVD technique using the standard mixture of $\mathrm{H}_{2} / \mathrm{CH}_{4}$ with an additional $\mathrm{H}_{2}$ flux passing through a bubbler containing a suitable concentration of $\mathrm{B}_{2} \mathrm{O}_{3}$ dissolved in methanol to assure films with acceptor concentration around $10^{21}$ $\mathrm{cm}^{-3}$. The growth times were 5, 7 and $10 \mathrm{~h}$ corresponding to samples $\mathrm{A}, \mathrm{B}$ and $\mathrm{C}$, respectively. Diamond quality, morphology and crystallinity were characterized by scanning electron microscopy (SEM), atomic force microscopy (AFM), Raman spectroscopy and $\mathrm{x}$-ray diffraction techniques. Electrochemical measurements were carried out from a Potentiostat Autolab PGSTAT 32 using solutions of $0,1 \mathrm{~mol} / \mathrm{L}$ de $\mathrm{Na}_{2} \mathrm{SO}_{4}, 0,1 \mathrm{~mol} / \mathrm{L} \mathrm{KNO}_{3}$ e $0,1 \mathrm{~mol} / \mathrm{L} \mathrm{Na}_{2} \mathrm{SO}_{4}+0,1$ $\mathrm{mol} / \mathrm{L} \mathrm{KNO}_{3}$.

The SEM and AFM analyses of diamond films showed the grain size increase as a function of the growth time, which are present in Fig. 1 for samples A and $\mathrm{C}$. The films $\mathrm{A}$ and $\mathrm{C}$ showed heterogeneity due to the competition among their crystallographic planes. The electrochemical response for nitrate reduction was obtained from cyclic voltammetry comparing the results for the three samples without and with nitrate addition.
The influence of the electrolyte composition may be observed in Fig.2. The hydrogen evolution is kept at the same potential region for the three electrodes without nitrate addition. Otherwise, in Fig $2 b$ with the nitrate presence, a negative shift in the potential region is observed mainly for electrode grown during $5 \mathrm{~h}$. This behavior is attributed to the morphologic difference among such samples. As the grain size decreases the $\mathrm{sp}^{2}$ content at the grain boundary increases promoting an easier diamond oxidation leading to an electrode surface that blocks the active surface sites.
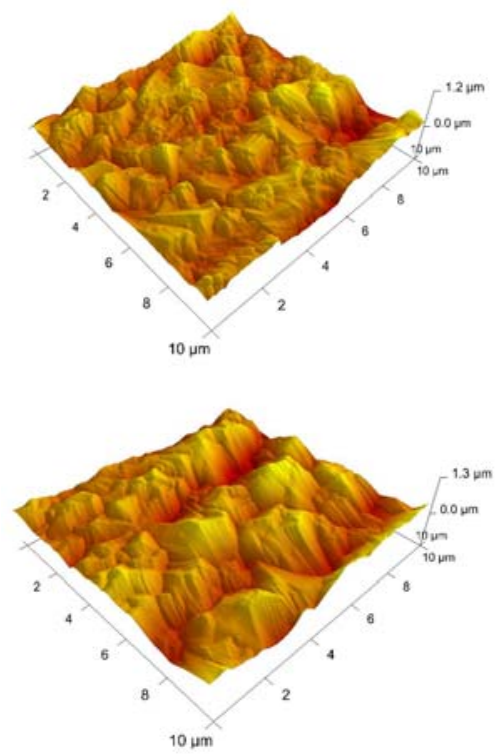

Fig.1. AFM images of samples A and C.

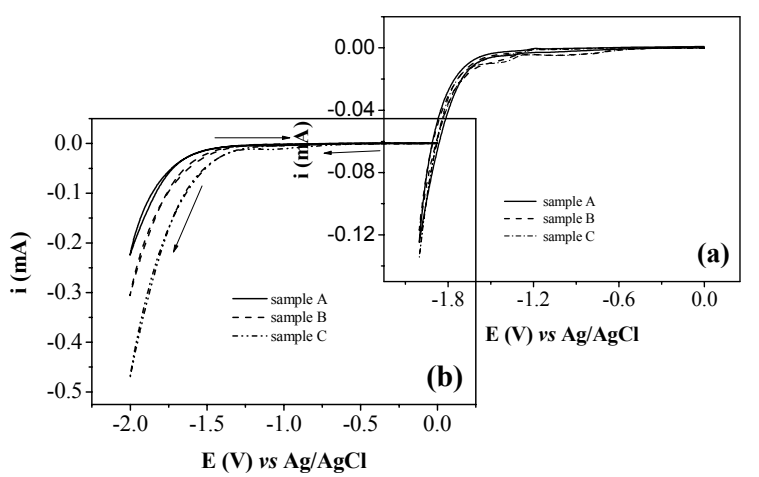

Fig.2. Cyclic voltammograms in solutions (a) $0,1 \mathrm{~mol} / \mathrm{L}$ $\mathrm{Na}_{2} \mathrm{SO}_{4}$ and (b) $0,1 \mathrm{~mol} / \mathrm{L} \mathrm{KNO}_{3}$.

[1] L. Monser, S. Sadok, G. M. Greenway, I. Shah, R. F. Uglow, Talanta, 57 (2002) 511.

[2] C. Levy-Clement, N.A Ndao., A. Katty, M. Bernard, A. Deneuville, C. Comninellis, A. Fujishima, Diam. Rel. Mat., 12 (2003) 606.

[3] C. M. Welch, M. E. Hyde, C. E Banks, R. G. Compton, Analyt. Sci., 21 (2005) 1421. 